Canadian Journal of Higher Education Revue canadienne d'enseignement supérieur

Volume 47, No. 1, 2017, pages 97 - 113

\title{
Exploring the Tensions and Ambiguities of University Department Chairs
}

Denise E. Armstrong and Vera E. Woloshyn

Brock University

\begin{abstract}
The department chair is a complex middle-management position located at the organizational fulcrum between faculty and senior administration. This qualitative study sought to develop a deeper understanding of chairs' experiences when enacting their dual roles as managers and scholars. Using a basic interpretative study design, we interviewed 10 department chairs from a medium-sized Canadian university. The participants identified three interrelated areas of challenge: managing position, managing people, and managing self. We discuss the tensions and ambiguities inherent within these themes, along with specific recommendations for supporting this position.
\end{abstract}

\section{Résumé}

Le poste de directeur de département est un poste de cadre intermédiaire complexe. Il se situe dans la sphère organisationnelle, comme un pont entre une faculté et l'administration supérieure. La présente étude qualitative vise à développer une meilleure compréhension du vécu des directeurs, qui doivent concilier le rôle de gestionnaire et celui de savant. Par le truchement d'une étude interprétative de base, nous avons interviewé dix directeurs de département d'une université canadienne de taille moyenne. Les participants ont relevé trois aspects liés aux défis rencontrés, soit la gestion du poste, la gestion des individus et la gestion de soi. Nous discutons des tensions et des ambiguïtés inhérentes à ces thèmes, et nous émettons des recommandations précises afin de bien encadrer les personnes qui comblent ce poste. 
In most Canadian postsecondary institutions, faculty are encouraged and expected to serve in a variety of leadership capacities, including that of department chair. Department chairs represent the largest administrative sector in higher education, and the quality and well-being of academic units are often attributed to their effectiveness (Normore \& Brooks, 2014; Wolverton, Ackerman, \& Holt, 2005). Worldwide, many universities are facing increased public scrutiny and are undergoing systemic changes consistent with corporate cultures that privilege marketization, efficiency, entrepreneurship, and executive-style leadership (De Boer, Geodegebuure, \& Meek, 2010; Normore \& Brooks, 2014). The interpenetration of business and educational values has created new challenges and ambiguities for middle managers such as department chairs, who are tasked with implementing new institutional policies, procedures, and directives while administering and representing their units (American Council on Education, 2014; Block, 2014; Carroll \& Wolverton, 2004).

While substantial advances have been made in understanding department chairs' duties and role expectations (Bryman, 2007; Czech \& Forward, 2010), this research originates primarily from the US. Furthermore, few studies have focused on the perspectives of role incumbents (for exceptions, see Acker, 2012; Berdrow, 2010; Boyko, 2009; Floyd, 2012), despite calls for such analyses (Boyko \& Jones, 2010). This is especially true for studies exploring the role enactment of the department chair within Canadian postsecondary institutions, where the position differs from its US and international counterparts in terms of its configuration as a largely temporary, service-oriented role, typically within a negotiated collective agreement (Boyko \& Jones, 2010). This article reports on the lived experiences of 10 department chairs at one Canadian university and the tensions and ambiguities they encountered in enacting their roles. We begin by drawing from U.S. and international studies to provide a brief overview of department chairs' roles and related challenges. We then review the research context associated with this study, provide an analysis of the relevant findings, discuss associated implications, and make recommendations for supporting department chairs.

\section{Department Chairs' Role Challenges}

It is well documented that the transition from a faculty position to department chair is a challenging yet important one (Gmelch, 2004; Jenkins, 2009). These difficulties, in part, reflect the paradoxical nature of moving from a co-equal to a managerial position (Armstrong, 2009) and the ambiguities inherent in department chairs' dual roles as administrators and academics (Carrol \& Wolverton, 2004). As the person in the middle, department chairs are accountable to senior administrators while simultaneously representing their faculty, student, staff, and departmental interests (Carrol \& Wolverton, 2004; Gmelch, 2004). These boundary-spanning and brokering functions are complicated further by institutional demands to complete numerous managerial tasks (e.g., developing structures, budgets, schedules, policies, and procedures) while providing leadership in terms of developing department culture and vision, nurturing faculty development, and fostering engagement (Berdrow, 2010; Bryman, 2007; Smith, Rollins, \& Smith, 2012). Furthermore, chairs are often caught in the political currents between senior administrators, faculty members, and unions, who often differ regarding the relative importance of these roles and how they should be enacted. For example, Gordon, Stockard, and Williford (1991) concluded that faculty members tend to evaluate chairs based on their ability 
to engage in and support research in their units, motivate others, and provide advocacy and advisement. Conversely, senior administrators increasingly are pressuring chairs to assume positions of oversight and "to adopt 'professional' management approaches and attitudes" (Meek et al., 2010, p. 1) that require them to manage resources, initiate program change, and problem solve in unilateral ways consistent with entrepreneur-based institutional objectives and initiatives (Meek et al., 2010). Ironically, in their service role as "first among equals" (Buller, 2012, p. 99), chairs are not accorded the institutional power required to effect these externally imposed changes.

Department chairs' tensions as front-line middle managers are exacerbated further by expectations associated with maintaining their personal research, teaching, and service agendas (Carrol \& Wolverton, 2004). Most chairs receive little advanced or ongoing guidance (Wheeler et al., 2008), relying predominantly on past practice (Gordon et al., 1991). They are poorly prepared to assume their positions, receiving substantially less training than senior administrators (Brown, 2001; Gordon et al., 1991). Finally, most incoming chairs have little understanding of these role expectations, task complexities, time demands, and the potential negative impact the role will have on their professional and personal relationships and identities (Aziz et al., 2005; Czech \& Forward, 2010). It is not surprising, then, that chairs report elevated stress levels due to bureaucratic uncertainty, workload demands, conflict with colleagues, research expectations, and organizational politics (Acker, 2012; Block, 2014; Floyd, 2012; Smith et al., 2012).

\section{Theoretical Framework}

Many studies show that the process of shifting from rank-and-file to middle-management positions is perhaps the most difficult transition a person can make, due to a variety of role and contextual factors, some of which have been discussed above. Our examination of department chairs' tensions and ambiguities is influenced by theories of career transition (Armstrong, 2009; Bridges, 2003; Hill, 2003) and organizational socialization that seek to understand how role changers adapt to changing professional and organizational norms. A career transition denotes a period when individuals are changing roles or their orientation to a role currently occupied (Louis, 1980). During this period, individuals may experience surprises, shocks, and contrasts as they cross unexpected personal, professional, and organizational boundaries while attempting to make sense of their new roles, relationships, and contexts (Armstrong, 2009; Bridges, 2003; Louis, 1980). Department chairs' transitions occur within organizational socialization contexts that impact role construction, orientations, and identities. While transition theories adopt an individual and internal perspective, socialization theories focus primarily on the tactics organizations use to inculcate individuals into normative organizational roles and identities-that is, how individuals acquire the knowledge, skills, and professional orientations needed to perform their assigned roles (Armstrong, 2009; Gmelch \& Parkay, 1999). When combined, both theories illuminate how role changers such as department chairs adapt to, resist, and integrate professional and organizational norms, values, expectations, and behaviours.

To date, most of the studies of department chairs' transitions have examined the move from faculty to chair through the lens of socialization (see, for example, Acker, 2012; American Council on Education, 2014; Foster, 2006; Gmelch \& Parkay, 1999). This research (e.g., American Council on Education, 2014; Foster, 2006; Gmelch \& Parkay, 1999) 
consistently portrays the move from academic to administrative roles as a challenging organizational and cultural shift requiring substantial adjustments. According to Foster (2006), becoming a department chair places faculty members at the boundary of the academic and administrative realms of the university. Bridging the boundaries between these two dimensions requires chairs to refocus from individual goals to broader group and institutional interests. Bennett (as cited in American Council on Education, 2014) identifies three main shifts that include moving from a specialist to a generalist perspective, working collectively versus individually, and balancing disciplinary and institutional needs. Academics experience these administrative shifts as an abrupt, difficult, and steep learning curve because they are typically socialized to focus on individual goals. The requirement to learn vast amounts of information and to navigate a complex variety of people, personnel, perspectives, programmes, policies, and procedures also introduces additional challenges (Foster, 2006; Gmelch \& Parkay, 1999). There is a general consensus that understanding department chairs' role transitions benefits individuals and the university. Gmelch and Parkay (1999) noted that changes in department chairs' professional identity begin as soon as they accept the position, and then continue during their tenure. By using individual and organizational lenses simultaneously, we hope to uncover the internal and external factors that influence department chairs' construction of their roles and identities within their external socio-cultural and political environments and the transitory context of their managerial role. Given the importance of this leadership position, this knowledge would benefit future chairs, improve policies and practices, and help to better prepare postsecondary

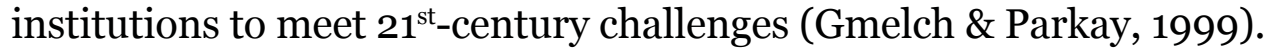

\section{Background to the Study}

In this study, we sought to gain a deeper understanding of how chairpersons in a medium-sized Canadian university made sense of and enacted the complex and conflicting roles associated with their leadership positions. Studies of middle managers in higher education, including department chairs, have suggested that the postsecondary landscape is becoming more complex and managerialist (Meek et al., 2010). These pressures, however, may unfold differently across institutional and global contexts. For instance, Boyko and Jones (2010) suggested that many Canadian chairs, unlike their counterparts in the US, Australia, and Europe, may be somewhat protected from pressures to conform to new managerialism practices due to their negotiated collective agreements. Thus, we were especially interested in exploring how a small group of Canadian chairs negotiated these tensions and ambiguities. Specifically, we explored the following questions:

1. What challenges, dilemmas, and tensions do Canadian department chairs experience?

2. What people, structures, and events do chairs identify as significant in supporting or hindering their transition?

3. What strategies do chairs employ to navigate this role?

\section{Method}

We used a basic interpretive qualitative design (Merriam, 2002) to explore 10 department chairs' reported experiences and understandings of their roles. Qualitative research 
does not seek to produce a representative and unbiased measurement of the views of a population, but rather to "ask general, open questions and collect data in places where people live and work" (Creswell, 2011, p. 43) and to listen to participants' views. Understanding a phenomenon from the perspectives of those who experience it, including the meanings they attribute to the phenomenon, is inherent to basic interpretative methodology, with these interpretations and meanings recognized as dynamic and potentially evolving over time and place (Merriam, 2002). To contextualize participants' perceptions and reports, and to familiarize ourselves with the duties and responsibilities associated with the position, we conducted an environmental scan that included a review of several relevant sources (e.g., collective agreement, faculty handbooks, and websites) prior to speaking with each participant. This analysis provided triangulation, thus increasing the trustworthiness and credibility of the research (Creswell, 2011). In these ways, our qualitative research offered a strong methodological framework for understanding multiple, socially constructed realities, as well as the complexities of individual and organizational dynamics as enacted through the chair's position (Creswell, 2011).

\section{University Context}

The chairs were recruited from a medium-sized, unionized Canadian university that was transitioning from being a predominantly teaching institute to a comprehensive one while experiencing budgetary restraints. The chairs' positions were elected, with the qualification that the three-year term (or a portion thereof) could be renewed by re-election. Each chair's primary duty, as defined by the university's collective agreement, was to represent their unit's interests. Other duties included providing academic leadership and mentorship, managing daily operations, submitting appropriate budgets to deans, and consulting department members about unit needs and goals. The chairs received, annually, a minimum of one full course reduction and a professional allowance stipend.

\section{Participants}

Participants in this study consisted of 10 department chairs (four females and six males) representing six faculties with varied faculty, student, and staff complements. Purposive sampling (Creswell, 2011) was used to recruit potential participants and involved providing all individuals serving as department chairs at the time of the study with a letter of invitation. Chairs who expressed interest in the study also were asked to nominate individuals whom they believed might be interested in participating in the study, and letters of invitation were forwarded to these individuals accordingly.

Three of the participants were completing their first year of term (Luke, Steve, and Richard), one was completing her second year (Susan), and five were completing their final year (Devan, Ellen, Graham, Kate, and Rachel). The remaining participant, William, had completed two consecutive terms as a chair (six years). Seven participants were associate professors and the remaining were full professors. Three participants had been employed at the university between five and 10 years, four between 10 and 20 years, and three for more than 20 years. Pseudonyms were assigned to all participants to maintain confidentiality. 


\section{Data Collection and Analysis}

Data collection occurred over a five-month period, with participants completing up to two 60-90-minute semi-structured interviews. Interviews focused on the participants' perceptions of the role of the department chair, the conditions that facilitated or hindered their role transition and enactment, and the changes experienced as a result of the position. All interviews were audio recorded and transcribed verbatim and were analyzed using the constant comparative method (Merriam, 2002).

Data analysis was thematic in nature and consisted of reading the interviews independently and holistically. Line-by-line analysis followed, allowing for the emergence of invivo codes as well as those corresponding to the research questions. A comparative table was used to identify similarities and differences across participants in order to arrive at convergent and divergent themes (Creswell, 2011). We then met to discuss our interpretations and arrived at a shared understanding of the emergent themes. As part of the member checking process, intended to enhance the overall trustworthiness of the study (Creswell, 2011), participants received copies of their transcribed interviews and associated interpretations and were invited to edit and clarify responses and associated themes. We received either minor or no requests for changes to the transcripts or the categories, suggesting that our recordings and interpretations were valid.

\section{Findings}

Our analysis identified several themes related to the chairs' perceptions of their roles and experiences, and the challenges and tensions they experienced. These challenges were clustered around three overarching areas of managing position, people, and self. Issues related to managing position included the quantity and diversity of the chairs' responsibilities, and the lack of training, power, and control. Managing people included interpersonal conflicts as well as resource acquisition and allocation. Finally, managing self involved balancing voice, maintaining scholarship, and understanding personal transformations. The most common tensions and ambiguities inherent within these three themes are discussed in the next section.

\section{Managing Position}

The participants described the transition from faculty member to department chair as overwhelmingly different and difficult due to the protean and ambiguous nature of their role and the lack of preparation for managerial tasks. As they reflected on their role, participants contrasted the difference in scope and responsibility of their previous foci on teaching and research with the challenge of adapting to the "newness" of the chair's role, and their lack of preparation for it. Kate reiterated participants' general experience of being "thrown in cold": "I had no idea about the details of the job. I had no idea about the management. I had no idea about what leadership issues would arise ... and the volume of information. There was all this newness." The chairs described their daily routines as often fragmented and unpredictable, and a contrast from their experiences as faculty. Like William, they identified a complex combination of factors, such as competing tasks, compressed timelines, and lack of control over their schedules, which resulted in extended workdays and feelings of fatigue, uncertainty, and pervasive anxiety: 
As a faculty member, I would do whatever work I had to do and get it done. As chair, your agenda is gone after a half an hour of showing up in your office. I would not get done what I wanted to get done that day. It meant working late or working at night or working on the weekend ... There was always something on my mind. What am I going to be hit with tomorrow morning? Am I going to get a phone call at home about this or that? Loss of my own agenda was something I had to adjust to.

The contrast between chairs' increase in status and workload and their loss of autonomy and power is reflected in Graham's comment: "You have a lot of responsibility and very little power. You're pulled in a number of different directions." Managing the volume and diversity of their workload while attempting to be visible and available surfaced additional tensions for chairs such as Peter, who noted: "I think the best strategy is the open-door policy and to be here regularly. It's difficult, so I've learned what kind of work I can do here, what kind of work I do at home." In spite of their commitment, managing the tensions of visibility and accessibility, as well as finding time to satisfactorily complete work during regular hours, created additional tension, particularly since the participants were also committed to maintaining scholarly productivity.

\section{Managing People}

Becoming a chair required frequent and ongoing interaction with a wider range of individuals and groups. Although communication was identified as a primary function of the department chair's role, participants often felt challenged by the unaccustomed volume and variety of information they received from multiple sources (e.g., students, colleagues, other department chairs, deans, senior administrators). While access to confidential information increased chairs' sense of power, it shifted their longstanding relationships and provoked ethical tensions related to how and to whom they should disseminate information. Luke explained: "As chair you become very acutely aware of what you can share and not share with people. I suppose you always have that as a faculty member to a degree but I think it's even more pronounced as a chair."

Part of the chairs' duties also involved liaising with and supporting others, including students, staff, colleagues, and senior administrators. For the most part, participants expressed appreciation for "key staff supports" (Luke) and believed that these individuals were critical to their role success because they held knowledge of the department's collective history, programming, and procedures. Indeed, many participants, such as Graham, indicated that they relied on assistance from staff when completing managerial tasks such as scheduling and timetabling: "The administrative assistants were very helpful ... they micromanage the department in terms of how it runs. . . they tell you: 'Oh, it's time for this,' or, 'It's time for that."' These participants viewed their relationship with staff as largely supportive and unproblematic. Participants also indicated holding positive relationships with students, typically in the role of advisor or advocate. At times, participants also assumed the role of mediator between students and faculty when differences arose with respect to instructional and/or performance expectations. Overall, such conflicts were relatively rare, with participants expressing the greatest concern about their interactions with their colleagues, as opposed to with students. 
Participants described their interactions with colleagues as requiring thoughtful consideration and being an ongoing source of tension. This, in part, was related to asserting managerial powers and balancing competing needs within a framework of collegial governance. In order to mediate the diverse personalities and interests of department members, the chairs reported having to assume unfamiliar roles as counsellors, supervisors, facilitators, and conflict managers, as Peter described: "Well, you're the guidance counsellor because you're doing mentoring, and then you're a psychotherapist, and then you wear a black and white shirt and carry a whistle because you're the referee." The discomfort associated with assuming these unaccustomed roles was exacerbated by the knowledge that their term as chair was limited. This tension is captured in Luke's description of how he carefully tempered his interactions in order to avoid damaging relationships with colleagues:

One of the things I'm conscious of is that you are chair for a limited time and then you return as a regular faculty member ... So whatever you have done as chair in terms of the relationships that you have forged with your colleagues, you're mindful of that because you want to make sure that you remain colleagues. As a chair you're always mindful that it is a temporary position and that fundamentally you are still colleagues with the people that you work with.

While the chairs' responsibility to work with all faculty members in their departments presented unique opportunities, such as forming satisfying new relationships, it also required working with "difficult" individuals. Devan highlighted the tensions that chairs experienced when obligated to work with colleagues with whom they would not typically associate: "There are some faculty members that I'm not going to have lunch with, and I'm not going to work with them on a research project ... But I will work with them when it's necessary." Mediating negative interactions between faculty members was also one of the chairs' most difficult and disliked responsibilities. This aversion to interpersonal conflict was captured by Devan:

There are certain people that don't get along, don't see eye to eye, that have to work together. And there are situations where people aren't talking with each other ... some people are in your face ... other people they get resentful ... you start to get a different perspective on your colleagues ... and I really resented that role.

Despite their distaste for such conflicts, participants were committed to resolving these disputes at the departmental level rather than "breaking ranks" and "going up the food chain" (Steve) by involving their deans.

Chairs also experienced tension when involved in direct conflicts with faculty members who overestimated the chairs' abilities to grant personal requests. Luke explained: "At times you have requests from colleagues who are requesting that certain things happen in terms of policies, developments, and things like that." Rachel also illustrated how attempts to balance program needs and faculty requests for special privileges created ethical tension, particularly when chairs tried to ensure equitable workloads:

It bothers me is when I see unfairness ... Something that I have no control over, and no one really has control over, is the people who don't pull their fair share and 
they're always trying to get you to get them a deal or to make it better for them. It's always about them and it's always at the expense of the department ... When you're dealing with performance issues, there's going to be conflict.

While participants generally attempted to resolve these personal and interpersonal tensions by avoiding direct confrontations with uncooperative colleagues, this strategy inevitably resulted in additional work for chairs. Graham's analogy of "herding cats" captures some of the frustration the chairs experienced when supervising faculty:

In some sense, it's kind of like herding cats . . . it's very hard sometimes, and it's frustrating. And people know that. They know that you don't have that much power, and therefore, if they don't want to do something, they don't.

Similarly, Peter, who compared himself to "the little red hen," reported that when asked, some faculty members either:

(a) don't do it, or (b) don't do it right, or (c) don't do it on time, which is the same as not doing it right. And then the department suffers ... So I end up doing it myself.

In this way, chairs' inability or reluctance to delegate subsequent tasks and the practice of "picking up the pieces" increased their workload and magnified their feelings of powerlessness and resentment.

In their role as departmental representatives, chairs also worked closely with other department chairs, deans, and senior management. While these interactions provided opportunities for mentoring and discussion of common issues, they also exposed chairs to a hyper-competitive, political arena where human and fiscal resources were not always negotiated fairly. One area of ongoing tension for chairs was the responsibility to secure resources for their departments and to protect them from budgetary cutbacks, as described by Graham:

There is a certain amount of fighting that goes on at the dean's level and at the university level to try to get resources for your department in a way that you think is fair. When there are dwindling resources, there's a kind of battle that goes on, and that's unpleasant.

Kate described an environment of "winners and losers, haves and have-nots" that often led to sleepless nights. Rachel also reported:

I'm not sleeping well because I know that in another year or two we are going to have some bottlenecks where I'm not going to have anything for some people to teach and I don't know what I'm going to do with them . . . it'd be terrible to lose some of these really prolific and great people.

These tensions were further exacerbated by the chairs' inability to influence senior management on behalf of their department and to share information about potential cuts with colleagues and students. 


\section{Managing Self}

The participants reported that exposure to the broader social, political, and policy landscape of their university impacted their perception of themselves, their unit, and the larger organization. Luke described how this cognitive shift impacted chairs' decision-making:

You have this wider view of possibilities and rules and regulations that are from outside that we have to conform to. Sometimes in terms of working with faculty or speaking with faculty as a chair you're thinking in terms of those wider contexts ... When you make one change to something often it causes ripples which impact on other areas and that can be frustrating.

While this privileged knowledge and perspective allowed the chairs to make more informed decisions, their increased feelings of accountability to and for others created cognitive dissonance. One such area of tension involved issues of personal and collective voice. The chairs described multiple tensions related to balancing their voice and that of the department, particularly when dealing with junior faculty or in cases where they disagreed with the department's collective voice. Luke connected these tensions to the development of a professional identity, which required determining priorities and developing awareness of one's own role and others' perceptions of it. He described how this required explicitly distinguishing between when chairs were expressing personal opinions as opposed to when they were speaking in their official capacity:

In terms of your professional identity you really have to get a handle on that. That's really critical. I think being very respectful, because you have to be aware that everyone you interact with is treating your comments from not just you as a person or a faculty member, but you as a chair ... even if you say, "Now I'm going to speak as a faculty member," you are still in the chair's role, and stepping out of that can be difficult.

Tensions related to collegial governance, democratic practice, and voice also surfaced when participants were faced with competing faculty agendas, especially when more powerful faculty members attempted to silence others. Devan described the challenge of including and respecting all voices, particularly those of junior faculty:

I want to make sure that when we do discuss issues that are brought to the table, that everybody has a voice and that everybody is included in the decision. Some people may not like it, but then they'll just have to. I don't like some of the things that have happened here, too. I just have to live with it.

While the chairs sought to maintain departmental solidarity, in some instances, they experienced ethical tension when faced with inequitable actions by colleagues. Like Peter, they reported "breaking ranks" in spite of repercussions from colleagues:

Once the department voted vehemently against the promotion and tenure of a colleague who deserved it ... They manufactured reasons why he or she shouldn't get it. It was so transparent and frustrating. I wrote the most scathing letter to the dean because it was so obvious that it was just vindictiveness. 
Tensions related to departmental voice and democratic processes also surfaced outside of their department in chairs' interactions with deans and other chairs (e.g., when deans pressured chairs to abdicate their departmental advocacy role). Rachel explained:

That is actually a really big part of how I see the job. I'm an advocate for our faculty and I think sometimes I run into conflict with the dean's office because ... they try to make us [chairs] side with them as opposed to be advocates for the employee group.

These incidents, though stressful, helped chairs to solidify their identity as their department's representative and to resist attempts to subvert faculty governance.

The chairs also reported that maintaining their dual identities as researchers and as managers was a pervasive source of tension. Unlike Luke and Susan, who were able to rely on previously completed and collaborative projects during their initial years as chair, the other chairs, particularly those who were ending their terms, experienced concerns about their decreased productivity and the long-term impacts on their scholarly careers, as illustrated by Kate's comments:

I definitely did less as a researcher, and that became progressively less over the years. And I found it very, very concerning to try to keep up any research agenda and I worried because you are always cognizant that you're only a chair for a small period of time.

When asked to reflect on their overall experiences, the participants agreed that assuming the position was transformative. For example, William reported that in spite of the negative conflicts with faculty and administration, becoming a chair allowed him to support and influence others positively, learn important interpersonal and managerial skills, and develop an in-depth understanding about how the university functioned. Similarly, Devan described developing increased organizational savvy, self-awareness, courage, and confidence:

I've learned a lot about both the university and myself, and I think I could take that and be a better faculty member ... stuff rolls off me that used to really hurt me in the past. You know, people saying things about my work, or about me. Now I know it doesn't matter.

This transformation, however, was not uniformly positive. While some chairs provided examples of long-term negative physical and emotional impacts experienced by others, Ellen and Peter spoke passionately about their personal situations. Ellen reported: "I just felt so disenchanted. I felt so alienated from my colleagues, from these friends, these people I'd worked with. I didn't even want to be there. I was so exhausted . . . I didn't recognize myself." Peter also reported negative outcomes: "It's not good for your wellbeing . . . Everybody complains about being the chair. Everybody does. It's sort of a standing joke that it's an onerous, thankless job." The next section further discusses these tensions and provides recommendations for improving the position of department chair.

\section{Discussion and Conclusion}

The findings of this study suggest that the position of department chair continues to be a complex one (Berdrow, 2010; Block, 2014) and further substantiate the existence 
of multiple factors inherent in the chair's role transition and socialization into managerial tasks that provoke ambiguity, stress, and strain (Berdrow, 2010; Normore \& Brooks, 2014). While we recognize that the relatively small number of participants and specific university context associated with this basic interpretative qualitative study inhibit the generalization of these participants' experiences to other department chairs, we believe that their experiences offer valuable insights into the experiences of others who assume this role within Canadian universities.

Research on middle managers in business and education confirms that new administrators experience role conflict, stress, and strain when required to manage dual identities, and that they need to divest themselves of their old identities in order to successfully navigate their transition and effect organizational change (Armstrong, 2009; Hill, 2003). Carroll and Wolverton (2004) concluded that many American department chairpersons perceive themselves as faculty members rather than chairs and are unwilling to commit to a managerial identity. Briggs's (2007) examination of the changing postsecondary context in the UK confirms that while understanding one's professional identity and that of other role holders is critical to effective administration, accomplishing this is a difficult task when organizations and roles are in flux. Specifically, the chairs in this study experienced personal and interpersonal conflicts in the process of managing their position, other people, and themselves. To a large extent, these conflicts can be traced to: the chairs' ambiguous location between faculty and senior management; the temporary, ill-defined, and precarious nature of this position; and their dual roles and identities as manager-scholars. Currently, the chair's role is a temporary and voluntary position in most Canadian institutions, with faculty assuming this transitory three- to five-year position out of a sense of obligation, altruism, or peer pressure. These role configurations and institutional practices should be reviewed, given that the requirement to return to the faculty ranks at the end of their tenure tempers chairs' willingness to address resistant colleagues and to establish stable professional identities as scholars, managers, or leaders. This reluctance may be connected to chairs' initial socialization as academics within a culture of collegial faculty governance, their lack of understanding of their role, and/or their reluctance to adopt a managerial identity within the context of a transitory role and a changing university context.

The participants received limited (or no) institutional preparation or support for the conflicting and changing demands of middle management. Normore and Brooks (2014) have argued that "the litany of managerial responsibilities" (p. 16) stymies chairs' ability to engage in leadership roles, and they suggested that senior management review recruitment and hiring policies, articulate the required leadership skills, and invest money in relevant professional development and training. Many studies have confirmed that chairs comprise the least-prepared management group within postsecondary institutions, and the researchers have called for relevant professional development (see, e.g., Aziz et al., 2005; Normore \& Brooks, 2014). Chairs are troubled by conflict, especially amongst colleagues, and they view conflict resolution as a difficult function of the position, if not the most difficult (Smith et al., 2012). Certain strategies may reduce chairs' tensions as they transition from faculty member to administrator: ongoing training in conflict management and priority setting; opportunities for job shadowing; workshops in budget preparation and timetabling (e.g., prior to fiscal year end, calendar submission deadlines); the instituting of positions such as associate chair. While we acknowledge the difficulty of predicting 
or agreeing on the kinds of duties and functions that department chairs should fulfill as this role evolves, we assert that conversations between chairs, senior administration, faculty, and/or unions need to occur in order to reduce role ambiguity so that universities can create a unique organizational space for chairs. These institutional dialogues can increase role holders' and others' awareness of this important role and potentially prepare faculty for the challenges and possibilities of middle-management roles and transitions.

Today's universities face ongoing challenges-such as declining funding, increasing entrepreneurial endeavours, globalization, and external demands for reform and accountability (Block, 2014; Meek et al., 2010) -and require innovative forms of leadership in order to succeed. Although the department chairship has been recognized as key to university administration, there has been little discussion about its leadership possibilities, with few attempts to maximize its potential (Brown, 2001; Stanley \& Algert, 2007). Unlike many of their counterparts in the US, Australia, and Europe, these Canadian participants largely resisted managerialist expectations and continued to perceive their position as a voluntary, service-centred one, focused on advocacy and representation. This perspective may be impacted by the existence of faculty associations and/or unions and their associated collective agreements that, in part, articulate and protect chairs' responsibility to represent their programs and departments (Boyko \& Jones, 2010). Within the participants' narratives, however, there are warning signs that aspects of new managerialism increasingly are impacting chairs' roles, despite collective agreements that support different ideologies and functions. Especially noteworthy were decanal pressures to adopt top-down, managerial approaches that contradicted democratic ideals, such as department autonomy and collegial governance, which were core to the chairs' initial socialization and their identities as faculty members and departmental advocates. Briggs (2007) described professional identity as "both a product and an agent of the systems and structures within which the individual's working life is located" (p. 473). His research confirmed that current British reforms have affected issues of professional identity on both individual and organizational levels. With increased pressures to participate in unilateral and undemocratic decision-making, the question arises whether faculty will continue to view the chairship as a service role versus a management career position, and how this perception will impact identity development.

Pervasive pressures related to amorphous and daunting workloads, as well as time and policy constraints, contribute to the inability of higher education to attract and retain chairs (Stanley \& Algert, 2007), and inhibit leadership capacity. Few chairs report aspirations to hold senior administrative positions, and the majority return to their status as faculty members after their tenure (Bryman, 2007; Smith et al., 2012). This is problematic, given the current "leadership crisis in higher education and the central nature of the department chair's role" (Stanley \& Algert, 2007, p. 66) to the sustainability of postsecondary institutions. Given the challenging and changing context of higher education, universities need to review recruitment and selection criteria and processes and ensure that incoming and practicing chairs have the leadership dispositions, competencies, and training required for this complex role.

The participants' experiences also identify the need for ongoing discussions across all institutional levels, and for universities to provide advanced leadership and management training, as well as support for chairs. Specifically, these department chairs' experiences highlight the need for targeted, time-sensitive, professional leadership development that 
includes formal and informal support groups for sharing confidential and sensitive issues with knowing and sympathetic others across the university (Brown, 2001; Gmelch, 2004). Similarly, chairs also need to assume responsibility for understanding their duties and responsibilities as related to their collective agreements and for capitalizing on this knowledge when confronted with ambiguity and/or responding to administrative demands. While we agree that preparation for role entry is insufficient, we believe that these chairs' concerns regarding role exit and re-entry into the faculty ranks also are an important and overlooked area of this transition (Smith et al., 2012). Support for role exit is essential, especially in light of the potentially detrimental emotional effects associated with the position.

We, like others (Acker, 2012; Aziz et al., 2005; Berdrow, 2010), advocate for continued research exploring chairs' experiences, particularly large-scale and longitudinal research that examines change over time and across different contexts and personalities in order to determine the impact of external socializing forces on chairs' duties, roles, and identities. Acker's (2012) analysis of the gendered dimensions of leadership in the academy confirmed that chairs' experiences and outcomes are influenced not only by their own intersecting and multiple identities but also by social and organizational structures that are "gendered, raced and classed" (p. 419), including other locations of difference. Such research can provide policy makers and aspiring and practising chairs with a broader and deeper understanding of the transition and socialization factors and processes that impact the movement into and from faculty to managerial roles, and the identity challenges and changes that are likely to accompany these role shifts.

This study confirmed previous findings and provided new understandings about the tensions and challenges associated with the department chair's position, as well as suggestions related to the future of this position. Multiple sources of conflict are built into department chairs' dual roles as academics and managers, and in their organizational location between faculty, students, and senior management (Stanley \& Algert, 2007), with the position remaining seemingly underappreciated and underused. Although higher education institutions in Canada and abroad face formidable leadership challenges, little has been done to clarify this role and to maximize department chairs' leadership potential. Chairs play a critical role in shaping the quality of educational programmes, and universities need to allocate more resources to ongoing and time-sensitive training and support of department chairs. Engaging in multilayered stakeholder discussions to improve this role, and instituting short-term and long-term research and planned interventions, can resolve many of the endemic tensions and ambiguities that department chairs experience, and build a solid foundation for effective postsecondary leadership and management.

\section{References}

Acker, S. (2012). Chairing and caring: Gendered dimensions of leadership in academe. Gender and Education, 24(4), 411-428.

American Council on Education. (2014). The role of the department chair. Retrieved from http://paid.uci.edu/chairs\%2oretreat\%20files/B.\%20Role\%20Of\%20the\%2oDepartment \%20Chair.pdf

Armstrong, D. (2009). Administrative passages: Navigating the transition from teacher to assistant principal. Studies in Educational Leadership (Vol. 4). Dordrecht, Netherlands: Springer. 
Aziz, S., Mullins, M. E., Balzer, W. K., Grauer, E., Burnfield, J. L., Lodato, M. A., \& Cohen-Powless, M. A. (2005). Understanding the training needs of department chairs. Studies in Higher Education, 30(5), 571-593.

Berdrow, I. (2010). King among kings: Understanding the role and responsibilities of the department chair in higher education. Educational Management Administration \& Leadership, 38(4), 499-514.

Block, B. (2014). Leadership and ambiguity: When policy, politics, and truth collide. Quest, 66(4), 323-337.

Boyko, L. (2009). An examination of academic department chairs in Canadian universities (Doctoral dissertation). Retrieved from https://tspace.library.utoronto.ca/ bitstream/1807/19122/3/Boyko_Lydia_M_200911_PhD_thesis.pdf

Boyko, L., \& Jones, G. (2010). The roles and responsibilities of middle managers (chairs and deans) in Canadian universities. In V. L. Meek, L. Goedegeburre, R. Santiago, \& T. Carvalho (Eds.), The changing dynamics of higher education middle management (pp. 83-102). Dordrecht, Netherlands: Springer.

Bridges, W. (2003). Managing transitions: Making the most change (2nd ed.). Cambridge, MA: De Capo.

Briggs, A. (2007). Exploring professional identities: Middle leadership in further education colleges. School Leadership \& Management, 27(5), 471-485.

Brown, L. (2001). Leading leadership development in universities: A personal story. Journal of Management Inquiry, 1O(4), 312-323.

Bryman, A. (2007). Effective leadership in higher education: A literature review. Studies in Higher Education, 36(6), 693-710.

Buller, J. L., (2012). The essential department chair: A comprehensive desk reference (2nd ed.), San Francisco, CA: Jossey-Bass.

Carroll, J., \& Wolverton, M. (2004). Who becomes a chair? New Directions for Higher Education, 126, 3-10.

Creswell, J. W. (2011). Educational research: Planning, conducting, and evaluating quantitative and qualitative research (4th ed.). Upper Saddle Creek, NJ: Pearson Education.

Czech, K., \& Forward, G., (2010). Leader communication: Faculty perceptions of the department chair. Communication Quarterly, 58(4), 431-457.

De Boer, H., Geodegebuure, L., \& Meek, V. (2010). The changing nature of academic middle management: A framework for analysis. In V. Meek, L. Goedegeburre, R. Santiago, \& T. Carvalho (Eds.), The changing dynamics of higher education middle management (pp. 229-242). Dordrecht, Netherlands: Springer.

Floyd, A. (2012). "Turning points": The personal and professional circumstances that lead academics to become middle managers. Educational Management Administration and Leadership, 2O(20), 472-284.

Foster, B. L. (2006). From faculty to administrator: Like going to a new planet. New Directions for Higher Education, 134, 49-57. doi:10.1002/he.216 
Gmelch, W. H. (2004). The department chair's balancing acts. New Directions for Higher Education, 126, 69-84.

Gmelch, W., \& Parkay, F. (1999, April). Becoming a department chair: Negotiating the transition from scholar to administrator. Paper presented at the Annual Meeting of the American Educational Research Association, Montreal, QC, Canada. Retrieved from http://files.eric.ed.gov/fulltext/ED430493.pdf

Gordon, B. G., Stockard, J. W., \& Williford, N. H. (1991). The perceived and expected roles and responsibilities of departmental chairpersons in schools of education as determined by teaching faculty. Education, 112(2), 176-182.

Hill, L. A. (2003). Becoming a manager: How new managers master the challenges of leadership. Boston, MA: Harvard Business School Press.

Jenkins, R. (2009). What new department chairs need to know. Chronicle of Higher Education, 56(9), 40-42.

Louis, M. R. (1980). Career transitions: Varieties and commonalities. Academy of Management Review, 5(3), 329-340.

Meek, V., Geodegebuure, L., Santiago, R., \& Carvalho, T. (2010). Introduction. In V. L. Meek, L. Goedegeburre, R. Santiago, \& T. Carvalho (Eds.), The changing dynamics of higher education middle management (pp. 1-14). Dordrecht, Netherlands: Springer.

Merriam, S. B. (2002). Qualitative research in practice: Examples for discussion and analysis. San Francisco, CA: Jossey-Bass.

Normore, A., \& Brooks, J. (2014). The department chair: A conundrum of educational leadership versus management. In A. Lahera, K. Hamdan, \& A. Normore (Eds.), Pathways to excellence: Developing and cultivating leaders for the classroom and beyond. Advances in Educational Administration (Vol. 21) (pp. 3-19). Bradford, UK: Emerald.

Smith, D. L., Rollins, K. B., \& Smith, L. J. (2012). Back to the faculty: Transition from university department leadership. Innovative Higher Education, 37, 53-63.

Stanley, C. A., \& Algert, N. E. (2007). An exploratory study of conflict management styles of department heads in a research university setting. Innovative Higher Education, 32(1), 49-65.

Wheeler, D. W., Seagren, A. T., Becker, L. W., Kinley, E. R., Mlinek, D. D., \& Robson, K. J. (2008). The academic chair's handbook (2nd ed.). San Fransisco, CA: Jossey-Bass.

Wolverton, M., Ackerman, R., \& Holt, S. (2005). Preparing for leadership: What academic department chairs need to know. Journal of Higher Education Policy Management, 27(2), 227-238.

\section{Contact Information}

Denise E. Armstrong

Department of Graduate and Undergraduate Studies, Faculty of Education Brock University

darmstrong@brocku.ca 
Denise E. Armstrong is an associate professor in administration and leadership in the Faculty of Education at Brock University. She has worked in K-20 institutions in Canada and the Caribbean and has written extensively on administrative transitions, educational leadership, ethics, and social justice. She authored Administrative Passages: Navigating the Transition from Teacher to Assistant Principal and co-authored three books: Working (with/out) the System: Educational Leadership, Micropolitics, and Social Justice; Leading and Mentoring for Educational Lives: Inviting Imaginative Acts of Hope; and Inclusion in Urban Educational Environments: Addressing Issues of Diversity, Equity and Social Justice.

Vera E. Woloshyn is a professor in the Faculty of Education at Brock University and current director of the Joint PhD Program in Educational Studies. Her research interests include working with individuals who experience learning difficulties, using popular media as a pedagogical tool, and role enactment within the helping professions. Over the years, Vera has held several administrative positions that have inspired her emergent interest in administrator identity and leadership experiences. 